\title{
Estatuto da Cidade e seus instrumentos de combate às desigualdades socioterritoriais: o Plano Diretor Participativo de Palmas (TO)
}

\author{
Statute of City and their Instruments to fight inequalities partner \\ territorial: the Palmas (TO) Director Plan Participatory
}

Germana Pires Coriolano ${ }^{[a]}$, Waldecy Rodrigues ${ }^{[b]}$, Adão Francisco de Oliveira ${ }^{[c]}$

[a] Mestre em Desenvolvimento Regional pela da Universidade Federal do Tocantins (UFT), professora do Curso de Arquitetura e Urbanismo da mesma instituição, Palmas, T0 - Brasil, e-mail: gerpires@gmail.com

[b] Doutor em Ciências Sociais pela Universidade de Brasília (UNB), professor do Curso de Economia e do mestrado em Desenvolvimento Regional da Universidade Federal do Tocantins (UFT), Palmas, TO - Brasil, e-mail: waldecy@terra.com.br

[c] Doutor em Geografia pelo Instituto de Estudos Sócio Ambientais (IESA) da Universidade Federal de Goiás (UFG), professor do Programa de Pós-Graduação em Geografia da Universidade Federal do Tocantins (UFT), Palmas, TO - Brasil, e-mail: adaofrancisco@gmail.com

\section{Resumo}

Palmas, a última cidade planejada do século XX, foi implantada seguindo uma lógica excludente de produção do espaço urbano, na qual a gestão territorial, à revelia do planejamento inicial proposto, confinou a população de baixa renda nas periferias da cidade, em áreas extremamente distantes do centro urbano, carentes de infraestrutura e de serviços públicos. Com base nessa perspectiva, esse artigo apresenta a análise de como o Plano Diretor Participativo de Palmas (PDPP), enquanto principal objeto de planejamento territorial, instituiu instrumentos de planejamento urbano voltados para reverter esse processo. Observou-se, na análise, que o PDPP apresentou conceitos e instrumentos voltados para reverter as desigualdades presentes no uso e na ocupação do solo urbano. Contudo, o descompasso entre o saber técnico e a vontade política, aliado à grande influência do capital imobiliário sobre as decisões políticas, reafirma as desigualdades socioterritoriais existentes na cidade, mantendo a lógica de segregação residencial da população de baixa renda.

Palavras-chave: Estatuto da Cidade. Plano diretor participativo. Palmas. Desigualdades socioterritoriais. Gestão urbana.

\section{Abstract}

Palmas, the last planned city of the twentieth century, was implemented following an exclusionary logic of production of urban space, in which the territorial management, in default of the initial planning proposed confined to low-income population in the suburbs, in areas extremely distant inner city, poor infrastructure and public services. Based on this perspective, this article presents an analysis of how the Master Plan Participatory Palmas (MPPP), as the main object of territorial planning, instituted urban planning 
instruments aimed to reverse this process. It was observed in analysis that MPPP presented concepts and instruments designed to reverse the inequalities present in the use and occupation of urban land. However, the gap between the technical knowledge and the political desire, coupled with the great influence of the real estate capital over political decisions, reaffirm existing socio-territorial inequalities in the city, keeping the logic of residential segregation of low-income population.

Keywords: Statute of City. Master plan participatory. Palmas. Socio territorial inequalities. Urban management.

\section{Introdução}

As desigualdades territoriais condicionadas pelo planejamento excludente provocam nas cidades uma série de problemas urbanísticos, sociais e ambientais, reproduzindo espaços desprovidos de infraestrutura e serviços públicos, com a formação de guetos sociais e a proliferação da violência urbana concentrada em áreas periféricas (MARICATO, 2000; OLIVEIRA, 2011; SOUZA, 2010). Segundo Oliveira (2012, p. 2), o planejamento excludente

consiste na condição de o planejamento urbano encerrar uma lógica eminentemente capitalista, uma vez que o seu empreendimento visa a racionalizar o ordenamento do território no sentido de nele se sedimentar todas as possibilidades para a realização do mercado. Contudo, o seu argumento não alude à ideia de mercado, mas à ideia de "Desenvolvimento Urbano", ou de "Crescimento Econômico". O seu caráter científico inscreve-se na análise sistemática da realidade urbana, intentando, a partir da identificação dos problemas que inibem o seu empreendimento, estabelecer as diretrizes político-jurídicas que o contemplam.

Tal condição do ordenamento territorial é característica das sociedades urbanas, sendo que no Brasil o processo de urbanização se intensifica a partir de meados do século XX, resultante da afirmação de uma lógica de industrialização e da redefinição do país na divisão internacional do trabalho (SANTOS, 2009).

Desse modo, no século XX, especialmente na sua segunda metade, o Brasil afeiçoou-se à lógica da sociedade urbana. Para Brito, Horta e Amaral (2010), isso é demonstrável no fato de, entre 1950 e 2000, a população urbana do país ter saltado de 18.782 .891 habitantes para 137.697.439 habitantes, multiplicando-se em 7,33 vezes com uma taxa média anual de crescimento de $4,1 \%$ e um incremento real médio anual de 2.378.291 habitantes. 0 resultado disso foi, obviamente, um forte inchaço urbano, de modo que os problemas disso decorrentes incitaram a população brasileira a se organizar em movimentos sociais, principalmente a partir da década de 1970, buscando melhor qualidade de vida do ambiente urbano.

Com a política de "distensão" do regime militar na primeira metade da década de 1980, houve um fortalecimento da luta pela redemocratização do Brasil e uma consequente ampliação das forças dos movimentos sociais, especialmente os populares urbanos. Isso não só provocou um intenso debate acerca da problemática urbana, como também fez emergir, já na segunda metade dessa década, importantes marcos normativos, especialmente a Constituição Federal de 1988. 0 Capítulo II da Constituição, que dispõe sobre política urbana, definiu o conceito de função social da propriedade e estabeleceu a obrigatoriedade de elaboração de planos diretores em municípios com população acima de 20 mil habitantes (MARICATO; SANTOS Jr., 2007).

Outro importante marco regulatório que se constituiu no principal instrumento da política urbana brasileira foi o Estatuto da Cidade, aprovado em 2001, que regulamenta os artigos 182 e 183 da Constituição Federal. 0 Estatuto estabeleceu o plano diretor como instrumento básico da política de desenvolvimento e expansão urbana, devendo definir os parâmetros de uso e ocupação do território, visando a seu ordenamento (BRASIL, 2001).

Esses instrumentos regulatórios, aliados à criação do Ministério das Cidades e do Conselho Nacional das Cidades em 2003, representaram importantes marcos institucionais para o estabelecimento 
de uma política nacional de desenvolvimento urbano, possibilitando a criação de diversos programas, como a Campanha Nacional do Plano Diretor Participativo, que apoiou os municípios na elaboração de seus planos diretores.

Nesse contexto, foi elaborado o Plano Diretor Participativo de Palmas (PDPP), Lei Complementar n. 155/2007, debatido entre os anos de 2006 e 2007 e sancionado em dezembro de 2007; é a lei que ordena o crescimento e o desenvolvimento sustentável do município de Palmas e estabelece a sua política urbana "com o objetivo de atender ao pleno desenvolvimento das funções sociais da cidade e a garantia do bem-estar de seus habitantes" (PALMAS, 2007). Sua elaboração buscou seguir a metodologia apresentada pelo Ministério das Cidades no contexto da Campanha Nacional do Plano Diretor Participativo ${ }^{1}$. Nesse sentido, concomitantemente com vários outros municípios, a elaboração do Plano Diretor de Palmas obedeceu a uma metodologia participativa, contando com o acompanhamento da sociedade civil organizada.

Assim, o objetivo central desse artigo é verificar o processo de elaboração do Plano Diretor Participativo de Palmas, bem como seu conteúdo, no que se refere aos instrumentos voltados para minimizar as desigualdades socioterritoriais, sob o ponto de vista das diretrizes do Estatuto da Cidade. Questiona-se em que medida esse importante instrumento do planejamento urbano foi elaborado ou não de acordo com os princípios de inclusão socioespacial preconizados pelo Estatuto da Cidade.

\section{Metodologia}

A análise baseou-se na metodologia elaborada pela pesquisa da Rede Nacional dos Planos Diretores Participativos realizada pelo IPPUR/Observatório das Metrópoles, cujo objetivo era a verificação de como os planos diretores elaborados pós-Estatuto da Cidade trataram: o acesso à terra urbanizada e aos serviços e equipamentos urbanos; o enfoque das políticas urbanas; e o sistema de planejamento e gestão democrática (SANTOS Jr.; MONTANDON, 2011). Destarte, também analisou a eficácia de instrumentos de indução ao desenvolvimento urbano, no intuito de garantir o acesso à terra urbanizada, a partir de um roteiro pré-definido, que enfocou principalmente os seguintes aspectos:

a) as diretrizes para cumprimento da função social da propriedade;

b) o controle do uso e da ocupação do solo;

c) a definição do perímetro urbano;

d) o parcelamento do solo;

e) o macrozoneamento;

f) a implantação de zonas especiais de interesse social (tipo de zonas, localização, acesso, regulamentação);

g) e os instrumentos de política fundiária.

Este artigo restringiu-se a analisar os instrumentos de indução ao desenvolvimento urbano, no intuito de minimizar as desigualdades socioterritoriais. Para tanto, considerou-se a análise do texto legal e das circunstâncias políticas de sua elaboração, por meio da realização de entrevistas. A análise considerou, ainda, os diversos atores presentes na arena, tais como os Poderes Executivo e Legislativo Municipais, especuladores imobiliários e movimentos sociais ligados à questão urbana.

Essa pesquisa tem como fundamento metodológico a compreensão de que a elaboração da política urbana e de seus instrumentos não se dá em um ambiente de neutralidade política ou administrativa, pois os conflitos de interesse constituem um aspecto permanente na produção do espaço urbano (LEFEBVRE, 1991).

\section{Breve caracterização do processo de ocupação urbana}

Palmas é a mais jovem capital do país, tendo nascido a partir de uma demanda político-administrativa surgida com a criação do Estado do Tocantins. Com uma população de 228.332 habitantes em

\footnotetext{
1 No período de 2005 a 2006, o Ministério das Cidades realizou uma ampla campanha nacional para a sensibilização de gestores públicos e da sociedade para a elaboração dos Planos Diretores.
} 
2010 (IBGE, 2010), essa capital possui 2.218,937 km² de área territorial. Entre 2000 a 2010, a população saltou de 137 mil para 228 mil habitantes, com um incremento demográfico de $66,2 \%$ no período, tornando-se num grande desafio para o assentamento urbano nos moldes do planejamento original da cidade.

Para além do incremento populacional significativo, Palmas foi uma das capitais de maior crescimento demográfico nessas duas últimas décadas. Isso preocupa pelo fato de que, embora tenha surgido a partir de um plano urbanístico, o processo de ocupação territorial de Palmas se deu diferentemente do que estava planejado (PALMAS, 2005).

Durante seu processo de ocupação, as terras escolhidas para a implantação da cidade foram compradas pelo Estado ou doadas por fazendeiros, transformando o Executivo Estadual no maior proprietário fundiário do município. Nessa perspectiva, o Estado comercializava as propriedades fundiárias com o capital imobiliário e utilizava as terras urbanas para negociar o pagamento das empreiteiras responsáveis pelas obras de construção da cidade. Enquanto isso, contraditoriamente, os trabalhadores que atuavam na construção civil da cidade eram obrigados a construir suas moradias longe da urbanidade do espaço formal (MORAES, 2003; CORIOLANO, 2011).

O Plano Diretor Urbanístico de Palmas ${ }^{2}$ previa uma densidade mínima de 300 habitantes por hectare, racionalizando a implantação da infraestrutura. Planejou-se uma ocupação por etapas sequenciais, na qual, com a ocupação de todas as áreas, a cidade chegaria a 38.400 hectares podendo abrigar aproximadamente 2,5 milhões de habitantes (Figura 1).

Apesar de ficar clara a intenção de promover uma ocupação ordenada e sequenciada, o que se observou foi um processo desordenado de ocupação do território, concentrando nas regiões centrais um grande número de vazios urbanos e nas regiões periféricas uma densa concentração da população de menor poder aquisitivo. A evolução da ocupação urbana desconsiderou o planejamento inicial da cidade, já no início da implantação. Com o aumento do número de imigrantes, o Estado colocou barreiras policiais nas entradas da cidade com o intuito de direcionar a população de baixa renda para a região sul, à revelia do plano urbanístico. A implantação da cidade ocorreu, por consequência, de maneira esparsa, provocando vazios urbanos e a prática da especulação imobiliária (CORIOLANO, 2011).

Prevista para expansão posterior, a região sul possui atualmente mais de $50 \%$ da população urbana de Palmas, concentrando maior quantidade de pessoas com menor poder aquisitivo e alta densidade demográfica. Bairros como o Aureny III, com a maior densidade populacional do município, possui em média $87 \%$ da população com renda de até três salários mínimos; da mesma forma, o Aureny IV possui $85 \%$ e os setores Morada do Sol e Sol Nascente possuem 91\% das famílias nessa situação. Tal cenário mostra claramente a segregação das famílias de baixa renda em áreas periféricas da cidade (CORIOLANO, 2011).

0 resultado desse processo é uma cidade fragmentada em parcelas, que apresenta duas realidades opostas: de um lado a cidade formal, rica em espaços de lazer, repleta de padrões e formalismos modernistas; de outro lado, a cidade informal, repleta de irregularidades, o "lugar dos excluídos". Os principais atores que atuam sobre esse processo são o capital privado e o Estado, ambos orientados pela dinâmica capitalista. Para Ribeiro (2005, p. 47), "há uma conexão estreita entre as características de nossas cidades e o padrão de desigualdades prevalecentes na sociedade brasileira. É a vigência dos clássicos mecanismos de acumulação urbana, cujos fundamentos são as próprias desigualdades cristalizadas na ocupação do solo".

\section{O PDPP e instrumentos urbanísticos para redução das desigualdades socioterritoriais}

O diagnóstico do PDPP identificou como um dos principais problemas urbanísticos a segregação socioterritorial na cidade. Nesse sentido, a maioria

\footnotetext{
2 Lei Municipal n. 468, de 6 de janeiro de 1994, Lei n. 468/94 - Plano Diretor Urbanístico de Palmas (PDUP). Artigo $7^{\circ}$, § 1.
} 


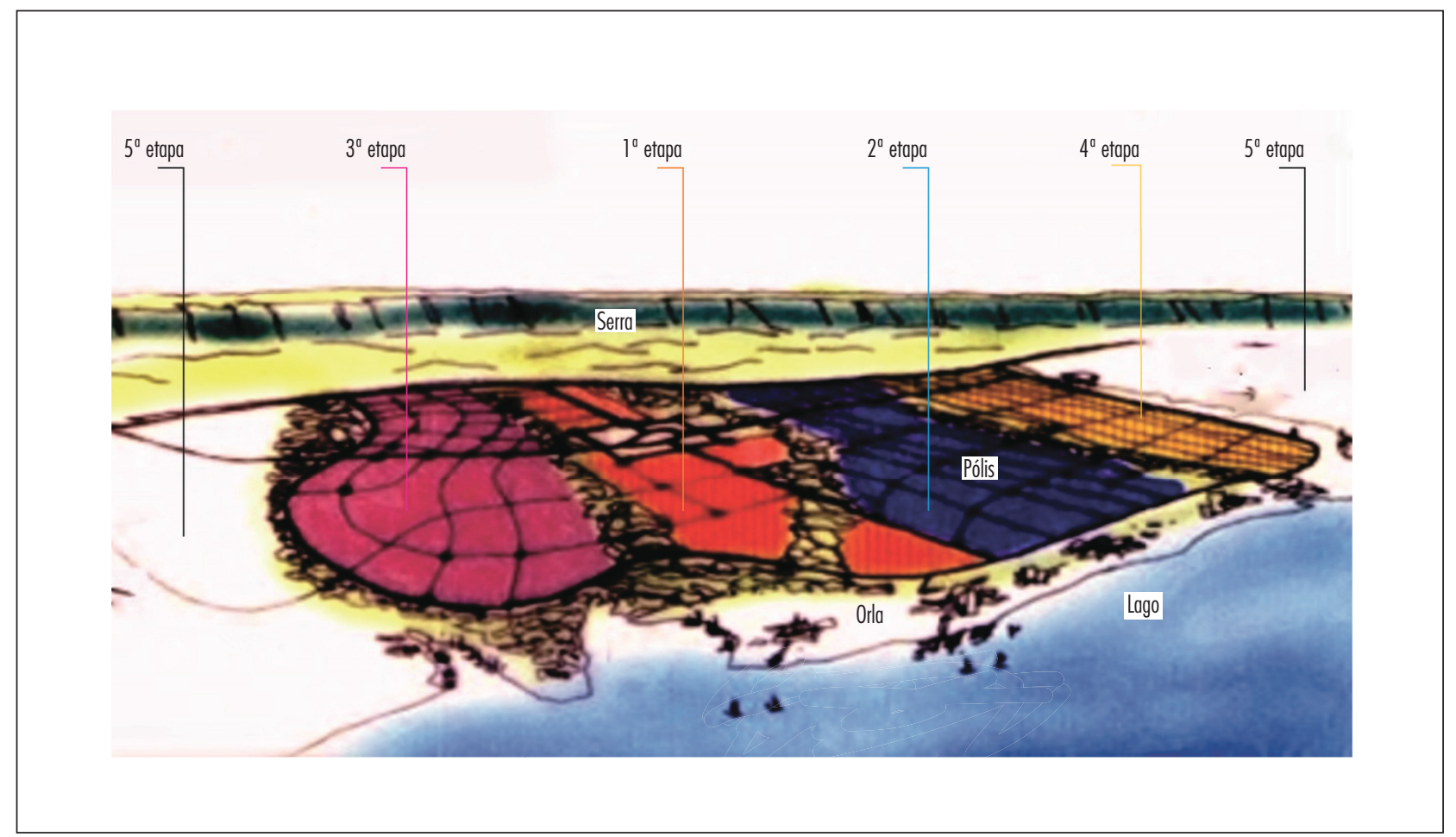

Figura 1 - Proposta de ocupação urbana sequenciada para Palmas

Fonte: Caderno Revisão do Plano Diretor de Palmas (PALMAS, 2005).

dos objetivos apresentados no plano busca, de alguma forma, reduzir as desigualdades e promover o acesso à terra urbanizada.

\section{A função social da propriedade urbana}

Para Santos Junior e Montandon (2011), o Plano Diretor tem como principal objetivo a definição da função social da cidade e da propriedade urbana, garantindo o acesso a terra urbanizada, bem como o direito à moradia, aos serviços urbanos e a uma gestão democrática e participativa.

Considerando que a FunçãoSocial da Propriedade é um princípio instituído pela Constituição Federal de 1988 (estabelecido em seu artigo 5o como uma das garantias fundamentais do cidadão) e que tanto a Constituição quanto o Estatuto da Cidade remetem sua definição ao Plano Diretor Municipal (BRASIL, 1988), o primeiro questionamento que buscamos responder é como o PDPP tratou essa questão.

0 PDPP (artigos 5 e 6을 estabeleceu a função social da cidade e da propriedade como o seu primeiro princípio, conceituando-o logo a seguir: "corresponde ao direito à terra, à moradia, ao saneamento ambiental, a uma cidade humanizada, à infraestrutura urbana, ao transporte e aos serviços públicos, ao trabalho, à cultura e ao lazer, para as presentes e futuras gerações" (PALMAS, 2007).

No artigo 7을 afirma que a propriedade urbana cumpre sua função social quando atende ao interesse coletivo expresso no plano e em suas leis complementares, devendo assegurar: o aproveitamento socialmente justo e racional do solo; a utilização adequada dos recursos naturais disponíveis, bem como a proteção, a preservação e a recuperação do meio ambiente; e o uso do solo compatível com a segurança e a saúde dos usuários e dos vizinhos.

Outro importante princípio considerado no plano (artigo 8우) é o da inclusão social, compreendida como a garantia da igualdade de oportunidades no processo produtivo, no acesso à moradia, ao lote urbanizado, ao espaço e aos serviços públicos, na educação, na cultura, no lazer e na gestão democrática (PALMAS, 2007).

Constata-se que o PDPP (artigos 12 e 13) avança ao conceituar seus princípios, apresentando elementos que objetivam a redução das desigualdades 
sociais. Isso acontece também na abordagem dos objetivos e dos temas prioritários, a maioria deles busca a garantia do "direito à cidade" e a redução das desigualdades, a partir do ordenamento do território e da promoção do acesso a terra urbanizada (PALMAS, 2007).

Instrumentos urbanísticos para a redução das desigualdades socioterritoriais

Visando à implementação de seus princípios e objetivos, o plano definiu uma série de instrumentos urbanísticos, dos quais alguns são apenas citados e outros apontam diretrizes para a implementação. Nesse texto, serão abordados aqueles tradicionalmente utilizados no planejamento urbano: macrozoneamento, perímetro urbano, parcelamento do solo e zoneamento; e os demais instrumentos do Estatuto da Cidade, voltados para a redução das desigualdades socioterritoriais: o parcelamento, edificação ou utilização compulsórios; o Imposto Predial e Territorial Urbano (IPTU) Progressivo no Tempo; a desapropriação com pagamentos em títulos e as Zonas Especiais de Interesse Social (ZEIS).

\section{Macrozoneamento e perímetro urbano}

Não existe uma metodologia clara para a definição de macrozoneamento. Os planos diretores tradicionais o apresentavam como um instrumento de divisão do município em urbano e rural. A partir do Estatuto da Cidade (artigo 40), que estabeleceu que o plano diretor deve incorporar o território do município como um todo (BRASIL, 2001), o macrozoneamento passou a ser entendido como um primeiro referencial para a territorialização das diretrizes do plano diretor, estabelecendo "um referencial espacial para o uso e a ocupação do solo na cidade, em concordância com as estratégias de política urbana" (BRASIL, 2002, p. 41).

0 macrozoneamento no PDPP definiu o perímetro urbano do município e dividiu seu território em Área Urbana, Área de Urbanização Específica e Área de Urbanização de Interesse Turístico e Rural (Figura 2).
É interessante observar, no mapa de macrozoneamento determinado pelo PDPP, que o perímetro urbano, representado em laranja, foi reduzido em relação ao estabelecido na lei anterior representado na Figura 3 pelas áreas demarcadas em laranja, rosa, vermelho e azul.

A estratégia de redução do perímetro urbano foi fundamental para o melhor aproveitamento da infraestrutura e o incentivo à ocupação dos vazios urbanos, tendo em vista que o diagnóstico do plano verificou grande quantidade de vazios, com uma ocupação rarefeita e, consequentemente, altíssimo custo de implantação e manutenção da infraestrutura e dos serviços urbanos (PALMAS, 2005).

0 macrozonamento avançou muito em relação ao anterior, principalmente no que se diz respeito ao perímetro urbano, contudo, observa-se a falta de diretrizes voltadas para a área rural, bem como para os distritos de Taquaruçu e Buritirama. Ressaltase ainda que, durante o processo de aprovação na Câmara Municipal, o perímetro ainda sofreu alterações, sendo incluída uma área denominada como Área de Urbanização de Interesse Turístico. 0 artigo 34 definiu a referida área:

Fica constituída como área de urbanização de interesse turístico a faixa de terra ao longo da margem do Lago de Palmas, com largura medindo 1.200 (um mil e duzentos) metros da cota 212, iniciando da Área de Serviço Regional Norte, fora do limite da zona urbana, até o Córrego Mirindiba, na divisa do município de Palmas com o município do Lajeado, tendo como limite máximo a TO-010, destinada a empreendimentos turísticos (PALMAS, 2007).

A criação dessa área teve como objetivo atender à demanda exclusiva do mercado imobiliário e pode acarretar, posteriormente, o aumento da demanda por infraestrutura e serviços públicos. Há de se considerar, ainda, que apesar da alteração identificada na Lei, o mapa apresentado, disponível no site da Prefeitura Municipal, não foi atualizado, não constando a área de urbanização de interesse turístico, portanto em desconformidade com a legislação, o que demonstra um indicativo de ineficiência da gestão pública.

A análise desses primeiros instrumentos nos apresenta avanços e retrocessos no que se diz respeito ao planejamento do território. A redução do 


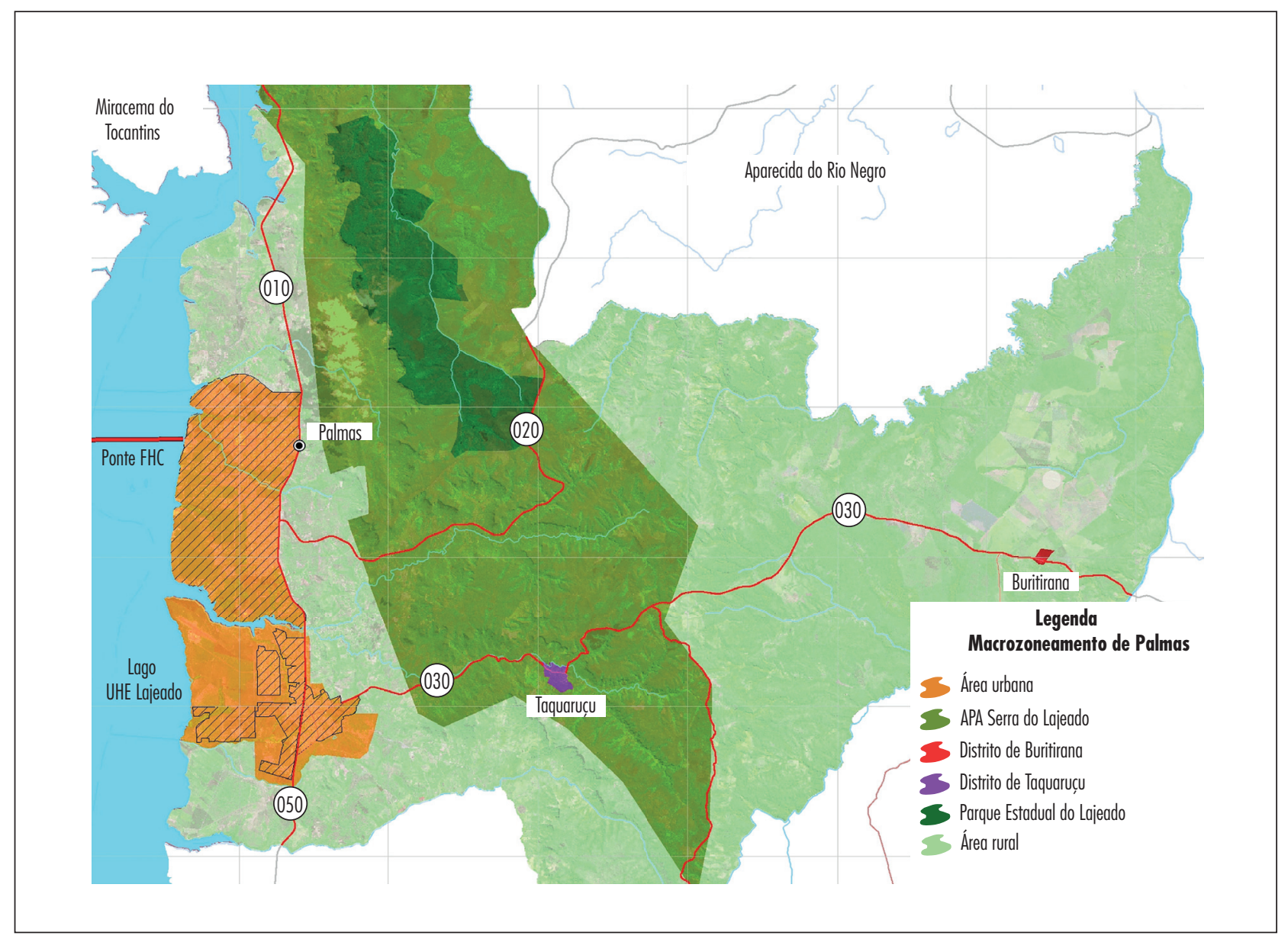

Figura 2 - Macrozoneamento do município de Palmas instituído pela LC-155/2007 (PDPP)

Fonte: PALMAS, 2007.

perímetro é apresentada como um grande avanço, se comparada com a de outros municípios que expandiram seus perímetros exclusivamente para atender a interesses privados, contudo, esse processo não ficou livre da intervenção do capital, haja vista a inclusão, sem critérios técnicos pré-definidos, da área de interesse turístico circundando toda a margem do Lago de Palmas, em uma iniciativa que busca privatizar os bens naturais existentes.

\section{Parcelamento do solo}

0 artigo 19 do PDPP remete a normatização do parcelamento do solo a uma legislação específica, mantendo vigente a lei anterior, na parte em que não foi tacitamente revogada. Até o momento, a lei complementar não foi elaborada, contudo o
Parágrafo $1^{\circ}$ deste artigo condiciona a aprovação de qualquer parcelamento ao atendimento das diretrizes e objetivos estabelecidos pelo plano, o que já significa algum avanço, tendo em vista que de um modo geral as diretrizes direcionam para um uso socialmente justo do território. Isso significa que Lei n. 468, aprovada em 1994, continua em vigor; contudo, considera-se que o PDPP revogou tacitamente os artigos que não condizem com suas diretrizes e seus objetivos.

Apesar de a Lei de Parcelamento não ter sido revisada, outras leis que a alteram foram elaboradas. Em 2009, foi aprovada a Lei n. 185, que prevê a flexibilização das áreas mínimas dos lotes no caso de habitação de interesse social, permitindo melhor aproveitamento dos terrenos, e possibilitando, ainda, a construção de um número maior de unidades habitacionais. Com isso, essa Lei permitiu o melhor 


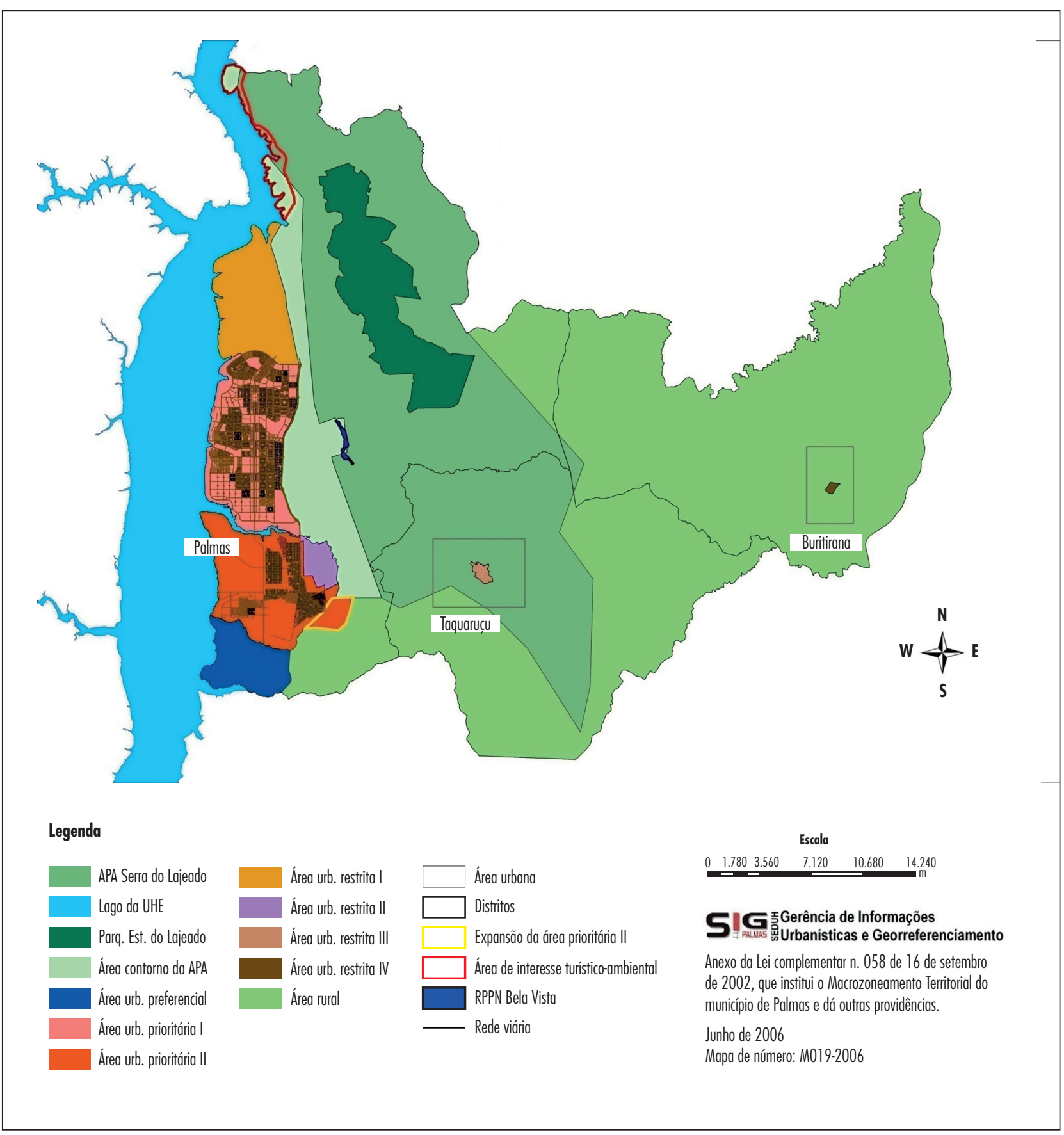

Figura 3 - Macrozoneamento do município de Palmas instituído pela Lei n. 58/2002

Fonte: PALMAS, 2002.

aproveitamento das áreas dotadas de infraestrutura e, também, a regularização de imóveis de padrão construtivo popular.

Já em 2012 foi aprovada a Lei Complementar n. 253, que alterou dois artigos do PDPP, sem a devida transparência e participação social preconizadas pelo Estatuto da Cidade. A Lei autoriza o município a alterar o uso de áreas verdes e de áreas públicas, desde que haja relevante interesse público ou administrativo, ou ainda, quando não mais se justificar urbanisticamente ou ambientalmente seus fins e objetivos originalmente previstos. No que se diz respeito às áreas públicas, o plano indicava que a alteração de uso deveria ser submetida à audiência pública coordenada 
pelo município. Em relação às áreas verdes, não eram previstas alterações de nenhuma forma. Nesse caso, foram feridos os seguintes princípios (artigo 8을 da Lei n. 155/2007 (PDPP): o da "proteção do meio ambiente e de seus bens comuns e vitais ao homem" e o da "democratização do planejamento e da gestão territorial" (PALMAS, 2007).

Mais uma vez, observou-se avanços e retrocessos na regulamentação do planejamento territorial. E mesmo no que se considera como avanço, verifica-se uma iniciativa pontual na busca pelo atendimento de demandas específicas. Quanto à alteração do plano, percebe-se uma clara manifestação do poder do capital sobre o interesse da coletividade, intervindo nas instâncias políticas a fim de beneficiar interesses privados.

\section{Zoneamento urbano}

Apesar de as diversas críticas atribuídas ao zoneamento enquanto instrumento de exclusão e segregação residenciais; no Brasil, principalmente a partir da década de 1980, ele foi pensado por técnicos e acadêmicos ligados ao pensamento de esquerda como um instrumento voltado para inclusão social, denominado por "zoneamento includente" ou "zoneamento de prioridades"3. Em contraste com o zoneamento tradicional, onde a preocupação central está na separação de usos e funções, o "zoneamento includente" busca identificar as áreas onde está localizada a população de baixa renda e classificá-las quanto à natureza do assentamento e conforme o grau de carência existente, direcionando a aplicação dos investimentos públicos (SOUZA, 2010). Afirma Souza (2010, p. 262): "foi na virada dos anos 80 para os anos 90 que um zoneamento de tipo diferente, explicita e prioritariamente voltado para a promoção social em áreas pobres, fez sua aparição, inspirado no ideário da reforma urbana".

O PDPP estabelece dois tipos de zoneamento: o Zoneamento de Uso e Ocupação do Solo Urbano e o Zoneamento de Ordenamento Territorial. 0 primeiro se caracteriza como o zoneamento tradicional, que tem por objetivo o estabelecimento de parâmetros para o uso e a ocupação do solo e o segundo busca estabelecer políticas prioritárias de investimento, o que poderia ser considerado como uma tentativa de se estabelecer um zoneamento de prioridades, conforme aponta Souza (2010).

o Zoneamento de Uso e Ocupação do Solo Urbano instituído no plano é remetido à legislação específica. 0 artigo 20 estabelece que a legislação atual (Leis n. 386/93 e n. 94/04) deverá ser revisada e indica diretrizes para isso. É interessante observar que existem duas leis que normatizam o uso do solo urbano. Uma se refere à região central e a outra à região sul da cidade, sendo os parâmetros estabelecidos por essas normas completamente diferentes para as duas regiões, o que reflete mais uma vez a discrepância no que diz respeito à unidade de cidade. Vale dizer que a Lei Complementar n. 94/04, que normatiza o uso do solo da região sul é uma lei mais flexível, enquanto a lei voltada para região central reflete parâmetros modernistas de planejamento.

Nesse caso, a diferenciação de tratamento das áreas é explicita: na região mais afastada do centro "cabe" uma legislação flexível, que atenda a população de menor poder aquisitivo, contudo, na região mais próxima ao centro a legislação é rígida, não permitindo flexibilizações, o que consequentemente acaba por elitizar o processo de ocupação.

o Zoneamento de Ordenamento Territorial apresenta elementos mais adequados à tentativa de reverter o quadro de exclusão social. Faremos uma análise do zoneamento proposto, a partir do Mapa de Ordenamento do Solo (Figura 4).

0 artigo 22 do PDPP estabelece como prioridade a ocupação das quadras inseridas nas "áreas estruturantes", que são áreas próximas aos eixos de deslocamento, de forma a garantir a ocupação e o adensamento prioritários e maximizar o aproveitamento dos investimentos públicos em infraestrutura, equipamentos urbanos e transportes.

A Lei observou também a localização de áreas produtivas integradas aos eixos de transporte, bem como a localização de áreas para habitação de interesse social. Foram criadas ainda, na Região Sul, onde está a maior concentração da população de menor poder aquisitivo, as Áreas de Serviço Regional com o

\footnotetext{
3 Denominado por Souza (2010) dessa forma, por ter como objetivo a inversão das prioridades para beneficiar a população menos
} favorecida e as áreas mais carentes. 


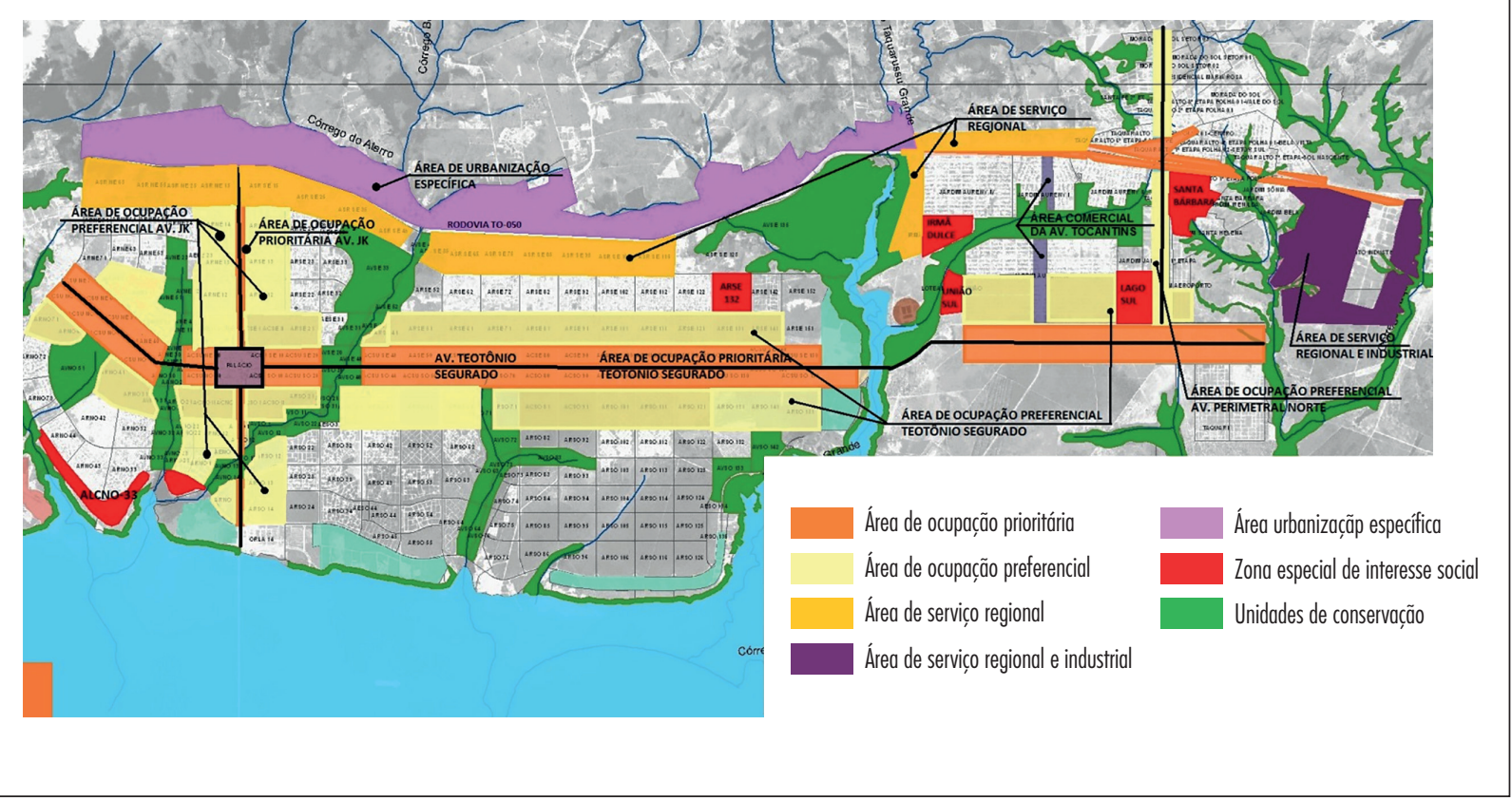

Figura 4 - Mapa do ordenamento do solo do município de Palmas aprovado pela Lei n. 155/2007 (PDPP)

Fonte: Adaptado de PALMAS, 2007.

intuito de gerar trabalho e renda para aquela população. Para cada uma das áreas delimitadas, o zoneamento estabeleceu diferentes objetivos:

a) Áreas de Ocupação Prioritária: localizadas nos eixos das Avenidas Teotônio Segurado, Via Auxiliar e JK, têm como objetivo o adensamento com alta densidade e maior coeficiente de aproveitamento do terreno. São áreas com infraestrutura, onde se estrutura o eixo de transporte, objetivando melhorar a acessibilidade da população e, consequentemente, o acesso aos bens e serviços urbanos, conforme Figura 4.

b) Áreas de Ocupação Preferenciais: localizadas nos eixos secundários das avenidas JK e Teotônio Segurado, e no eixo da Avenida Perimetral Norte na Região Sul de Palmas, têm como objetivo o adensamento de média densidade;

c) Área Comercial da Avenida Tocantins: voltada para média e alta densidade, com predominância do uso comercial.

d) Área de Serviço Regional: além das áreas já consolidadas na região central, o plano definiu outras áreas na região sul, onde está concentrada a população de menor poder aquisitivo e possui o maior índice de desemprego, voltadas para a implantação de grandes equipamentos comerciais e industriais;

e) Áreas de Urbanização Específica: localizada às margens da rodovia, destinadas à implantação de equipamentos de maior porte, como indústrias de menor impacto ambiental, postos de combustível e hotéis.

Conforme apresentado, o Zoneamento de Ordenamento Territorial apresenta avanços, induz à ocupação ordenada do solo urbano e remete ao uso socialmente justo do território, tendo como referência o adensamento das áreas urbanizadas e dos eixos de transporte, bem como a geração de emprego, trabalho e renda nas áreas mais adensadas, com o maior índice de desemprego.

\section{Zonas Especiais de Interesse Social (ZEIS)}

As ZEIS têm como finalidade a identificação de áreas vazias onde poderão ser implantados programas habitacionais e de assentamentos irregulares, 
para a promoção da regularização fundiária (urbanística, administrativa e jurídica), podendo se configurar em um importante instrumento de inclusão da população (ROLNIK, 2007).

A proposta de ZEIS elaborada pela Prefeitura Municipal buscou considerar as áreas vazias existentes dotadas de infraestrutura, as áreas irregulares e os loteamentos regulares com carência de infraestrutura, nos quais, por meio de parceria com o loteador, seria possível a permuta de áreas para implantação de programas habitacionais em troca da implantação de infraestrutura ${ }^{4}$. Foram consideradas quatro tipos de zonas no projeto de lei apresentado à Câmara Municipal: ZEIS tipo 1 - glebas urbanas, públicas ou particulares, para fins de loteamentos de interesse social; ZEIS tipo 2 -loteamentos regulares aprovados ou não, sem infraestrutura completa, passível de consórcio e parcerias com o poder público, visando à construção de habitações de interesse social; ZEIS tipo 3 - loteamentos irregulares para fins de regularização; e ZEIS tipo 4 - lotes multifamiliares (HM), vazios e/ou subutilizados, com infraestrutura básica localizados em quadras dentro da Área de Ocupação Preferencial Avenida JK e da Área de Ocupação Preferencial Av. Teotônio Segurado
(PALMAS, 2006). Apesar do Projeto de Lei apresentado pelo Executivo, a Câmara Municipal excluiu do seu texto uma grande parcela das áreas destinadas às ZEIS tipo 1 e na totalidade as ZEIS tipo 4 (Figura 5).

Das áreas apresentadas pelo Executivo Municipal como ZEIS tipo 1, permaneceram somente a ALCNO-33 e 43 e foi incluída a quadra ALCNO-13. Isso se justifica por que as demais áreas passam por um intenso processo de valorização imobiliária e as que foram mantidas eram áreas de propriedade do Estado do Tocantins, onde já havia a previsão de aplicação de recursos do PAC (Programa de Aceleração do Crescimento), voltados para habitação de interesse social. Portanto, a instituição de ZEIS era conveniente. Ressalta-se ainda que, apesar de essa área se localizar em uma região central, é uma área ambientalmente frágil e estava regulamentada na Lei de Uso e Ocupação do Solo (Lei n. 386/1993) como Área de Lazer e Cultura (ALC). Tendo em vista que essa região sofreu um processo de ocupação, no início da implantação da cidade, por população de baixa renda, infere-se que o Estado não tinha a intenção de localizar a população de menor poder aquisitivo em áreas próximas à infraestrutura, e sim de localizá-los em uma região já ocupada por

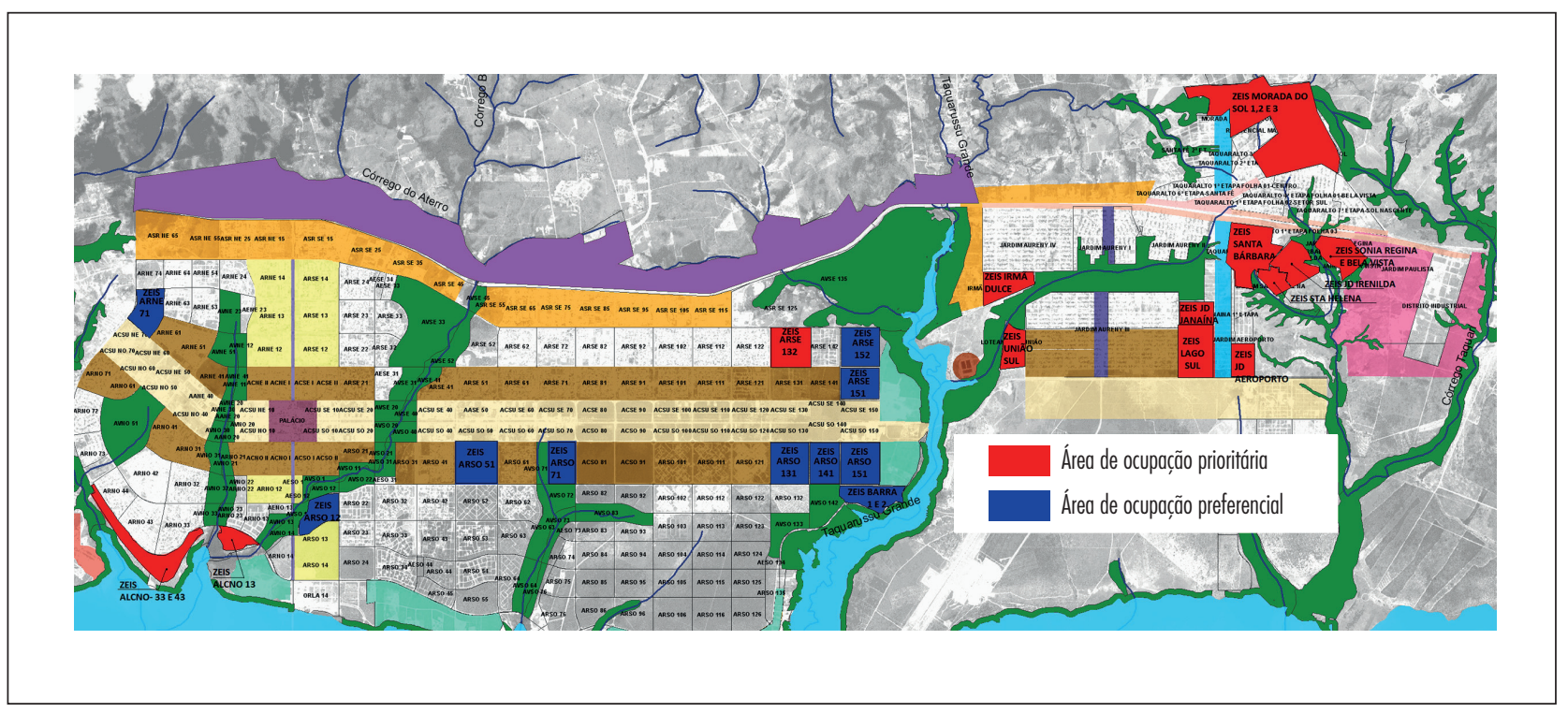

Figura 5 - Identificação das ZEIS propostas e aprovadas pela Lei n. 155/2007 (PDPP)

Fonte: Adaptado de PALMAS, 2007.

\footnotetext{
4 Entrevista concedida por Cesar Amaral, coordenador técnico do PDPP, em 12 de abril de 2011.
} 
população dessa faixa de renda, mantendo o processo de diferenciação socioterritorial.

Na região centro-sul, o Executivo propôs a implantação de várias ZEIS tipo 1, porém a única que foi mantida foi a da ARSE-132, que possui uma localização privilegiada em relação à maioria das ZEIS, onde o comércio é pujante e o entorno está dotado de infraestrutura, serviços e equipamentos públicos. 0 principal motivo da manutenção foi por esta ser de propriedade do Movimento Nacional de Luta pela Moradia - MNLM, que, após um processo de ocupação organizada e despejo forçado, pressionaram o governo estadual e conquistaram o direito de propriedade.

A ZEIS tipo 2 é composta por loteamentos aprovados ou não, com carência de infraestrutura, para a implantação de moradias populares. Os loteamentos incluídos nesse tipo de ZEIS são: Morada do Sol (Setor I, Setor II, e Setor III), Jardim Janaína, Jardim Aeroporto, Santa Fé - 2a Etapa, Lago Sul, Jardim Santa Helena, Jardim Sônia Regina e Jardim Irenilda. Observa-se que a localização dessas ZEIS é extremamente periférica e as áreas não possuem infraestrutura, sendo incondizente com as diretrizes apresentadas no PDPP, reafirmando a segregação socioterritorial.

Além das áreas descritas acima, foram demarcadas como ZEIS tipo 3, para fins de regularização fundiária, os loteamentos: Irmã Dulce e União Sul, localizados na região sul de Palmas, e o Santo Amaro, na região norte, áreas de domínio do Estado do Tocantins, parceladas irregularmente.

Ao comparar o que foi excluído com o que foi apresentado pelo Executivo, verifica-se a intenção de o Executivo municipal promover a inclusão social, buscando ocupar os vazios urbanos. Contudo, não diferente dos demais municípios brasileiros, o interesse do mercado sobressai ao da coletividade, tornando a terra urbanizada, mesmo que pública, inacessível à população de baixa renda.

É interessante observar que na região sul, mais afastada do centro, onde estão localizadas as famílias de menor renda, foram mantidas todas as áreas propostas como ZEIS tipo 2. Ressalta-se que tal manutenção é de interesse do mercado, tendo em vista que a implantação de moradias populares proporciona a aplicação de investimentos públicos nas áreas periféricas e, consequentemente, a valorização dos vazios urbanos que estão localizados entre essas e as áreas centrais.

De acordo com o vereador e representante do MNLM, Bismarque Roberto ${ }^{5}$, o processo na Câmara de Vereadores aconteceu por "debaixo dos panos". Apesar de o processo de elaboração do plano ter se dado de forma participativa, com o envolvimento da comunidade, por meio das diversas reuniões realizadas, os movimentos e o Executivo municipal foram excluídos do processo na câmara, o que resultou na distorção deste instrumento, dentre outros problemas constatados nesta análise.

0 coordenador técnico do plano, Cesar Amaral ${ }^{6}$, considera ainda que a participação reduziu no fim do processo, o que prejudicou o controle social sobre o processo na Câmara Municipal.

Parcelamento, Edificação e Utilização

Compulsórios (PEUC), IPTU Progressivo no Tempo

e Desapropriação com Pagamentos em Títulos

O Capítulo II, do Título VII do PDPP estabelece que todos os imóveis subutilizados, em áreas dotadas de infraestrutura, localizadas nas Áreas de Ocupação Prioritária e Preferencial (Figura 4) poderão ser passíveis de aplicação de Parcelamento, Edificação e Utilização Compulsórios (PEUC), seguidos do IPTU Progressivo no Tempo e da desapropriação com pagamentos em títulos.

Os instrumentos objetivam proporcionar o uso adequado aos imóveis ociosos e estabelecer a forma de notificação, devendo ainda instituir o prazo máximo de um ano, para que os proprietários de imóveis nesta situação protocolem na Prefeitura um processo para aprovação de projeto de parcelamento ou edificações. 0 prazo para início das obras se estende por mais dois anos, a partir da aprovação

\footnotetext{
5 Informações retiradas de entrevista concedida por Bismarque Roberto de Sousa Miranda, atual vereador de Palmas e coordenador do Movimento Nacional de Luta pela Moradia, no momento de elaboração do PDPP, concedida em 17 de junho de 2011.

${ }^{6}$ Entrevista concedida por Cesar Augustos de Santis Amaral, coordenador técnico do PDPP, arquiteto da Prefeitura de Palmas, em 12 de abril de 2011.
} 
do projeto. Ou seja, todo o proprietário tem no mínimo três anos para dar um uso adequado ao imóvel.

O IPTU Progressivo no Tempo é uma penalidade para os proprietários que não fizerem o uso adequado dos terrenos no prazo estabelecido, devendo ser cobrado durante cinco anos, com a alíquota graduada de forma progressiva. Passados os cinco anos, se o proprietário não der o devido uso ao imóvel, o município poderá desapropriá-lo com pagamentos em títulos da dívida pública (BRASIL, 2001).

Esses instrumentos conjugados demandam tempo para avaliar os resultados, contudo, se bem aplicados, acarretarão na regulação do valor do imóvel, podendo torná-los mais acessíveis à população, além de proporcionar ao poder público a destinação de terrenos para a implantação de programas habitacionais.

A Prefeitura de Palmas elaborou uma norma complementar para regulamentar o PEUC e o IPTU Progressivo, a Lei complementar n. 195/2009. A lei dividiu a aplicação do instrumento em etapas sucessivas de notificações de acordo com o disposto no PDPP. A lei considerou, na primeira etapa, o parcelamento compulsório voltado para todas as áreas de ocupação prioritária e preferenciais (Figura 4), e, para edificação compulsória, restringiu às áreas mais centralizadas, que seriam as faixas próximas às principais avenidas Teotônio Segurado e JK, dotadas de infraestrutura urbana.

Apesar de a lei ter sido aprovada em 2009, somente no ano de 2011 os proprietários dos imóveis foram notificados. Esta análise se restringiu à primeira etapa de sua implementação, tendo em vista a falta de informações sobre o andamento dos processos e a inexistência de resultados possíveis de serem mensurados. Contudo, considera-se que a estratégia de dividir em etapas de aplicação, iniciando com as áreas dotadas de infraestrutura, próximas aos principais eixos viários e de transporte, foi interessante no sentido de adensar essas áreas e de tornar o instrumento viável para a aplicação, tendo em vista a grande quantidade de vazios urbanos existentes na cidade.

\section{Considerações finais}

0 principal questionamento que se buscou responder neste trabalho foi se o planejamento territorial tem sido efetivo, no sentido de reverter a lógica excludente de produção da cidade, a partir da leitura dos instrumentos urbanísticos instituídos pelo plano diretor.

Verificou-se, de modo geral, que a Lei do PDPP apresenta conceitos, propõe políticas e instrumentos que buscam a inclusão da população baixa renda, avançando em relação a muitas experiências brasileiras.

A estratégia de ordenamento territorial é condizente com aquilo que se compreende como um zoneamento includente, ou seja, busca flexibilidade das funções e demarca áreas para a aplicação do IPTU progressivo e das ZEIS. Entretanto, observa-se que, durante a aprovação na câmara, as alterações sofridas foram muito prejudiciais ao seu conteúdo.

Observou-se ao analisar as ZEIS, que apesar da tentativa do executivo de implanta-las em áreas centrais, a lei aprovada priorizou localizações mais afastadas, reafirmando a lógica de segregação residencial da população de baixa renda nas "franjas da cidade". Mais uma vez, o que temos observado é uma grande valorização dos imóveis centrais subutilizados, incentivada ainda mais pela implantação de infraestrutura e de equipamentos urbanos nas áreas periféricas da cidade, tendo como consequência o alto custo da infraestrutura, onerando os cofres públicos.

Percebeu-se que ocorre um movimento de incentivo à implantação de políticas públicas para reverter as desigualdades socioterritoriais, contudo, os instrumentos de planejamento territorial ainda se submetem aos interesses do capital imobiliário, dificultando a concretização dos objetivos contidos no plano. Isso se dá, principalmente, pela pressão provocada no poder público para o atendimento de interesses privados, mascarada pela disseminação do discurso da promoção do "desenvolvimento econômico", diante da falta de apropriação dos instrumentos democráticos pela sociedade civil organizada e, consequentemente, pela não implementação dos instrumentos que poderiam garantir o cumprimento dos objetivos do PDPP, prevalecendo a lógica da produção capitalista ante a uma tentativa de planejamento includente e participativo.

\section{Referências}

BRASIL. Constituição (1988). Constituição da República

Federativa do Brasil. Brasília: Senado Federal, 1988. 
BRASIL. Lei n. 10.257, de 10 de julho de 2001. Regulamenta os arts. 182 e 183 da Constituição Federal, estabelece diretrizes gerais da política urbana e dá outras providências. Diário Oficial [da] República Federativa do Brasil, Brasília, DF, 11 jul. 2001. Disponível em: <http://www.planalto.gov.br/ccivil_03/leis/LEIS_2001/ L10257.htm>. Acesso em: 25 out. 2013.

BRASIL. Estatuto da Cidade: guia para implementação pelos municípios e cidadãos. Brasília: Câmara dos Deputados, 2002.

BRITO, F.; HORTA, C. J. G.; AMARAL, E. F. L. A urbanização recente no Brasil e as aglomerações metropolitanas. 2010. Disponível em: <http://www.nre.seed.pr.gov.br/ cascavel/arquivos/File/A_urbanizacao_no_brasil.pdf>. Acesso em: 22 mar. 2010.

CORIOlAnO, G. P. Plano Diretor Participativo de Palmas: análise da aplicação de instrumentos urbanísticos para a redução das desigualdades socioterritoriais. 2011. Dissertação (Mestrado em Desenvolvimento Regional e Agronegócio) - Universidade Federal do Tocantins, Palmas, 2011.

OLIVEIRA, A. F. Heterotopia, democracia e gestão urbana: desigualdades socioterritoriais e participação sociopolítica em Goiânia (1997-2008). 2011. Tese (Doutorado em Geografia) — Universidade Federal de Goiás, Goiânia, 2011.

OLIVEIRA, A. F. Goiânia: planejamento, segregação e descentralização seletiva. 2012. Mimeografado.

LEFEBVRE, H. 0 direito à cidade. São Paulo: Ed. Moraes, 1991.

MARICATO, E; SANTOS JUNIOR, O. A. Construindo a Política Urbana: participação democrática e o direito à cidade. In: RIBEIRO, L. C. Q.; SANTOS JUNIOR, O. A. (Org.). As metrópoles e a questão social brasileira. Rio de Janeiro: Editora Revan, 2007. p. 165-195.

MARICATO, E. As ideias fora do lugar e o lugar fora das idéias: planejamento urbano no Brasil. In: ARANTES, O.; VAINER, C.; MARICATO, E. (Org). A cidade do pensamento único: desmanchando consensos. Petrópolis: Vozes, 2000. p. 121-192.

MORAES, L. M. A segregação planejada: Goiânia, Brasília e Palmas. Goiânia: Editora da UCG, 2003.
PALMAS (Prefeitura municipal). Caderno de Revisão do Plano Diretor de Palmas. 2005. Mimeo.

PALMAS (Prefeitura municipal). Lei Municipal n. 468, de 6 de janeiro de 1994. Aprova o Plano Diretor Urbanístico de Palmas (PDUP) e dispõe sobre a divisão do solo do município, para fins urbanos. Palmas, T0, 6 jan. 1994. Disponível em: <www.leismunicipais.com.br/a/ to/p/palmas/lei-ordinaria/1994/46/468/lei-ordinaria-n-468-1994-aprova-o-plano-diretor-urbanistico-de-palmas-pdup-e-dispoe-sobre-a-divisao-do-solo-do-municipio-para-fins-urbanos-1994-01-06.html>. Acesso em: 25 out. 2013.

PALMAS (Prefeitura municipal). Lei complementar n. 058, de 15 de setembro de 2002. Institui o Macrozoneamento Territorial do Município de Palmas. Palmas, T0, 15 set. 2002. Disponível em: <www.leismunicipais. com.br/a/to/p/palmas/lei-complementar/2002/5/58/ lei-complementar-n-58-2002-institui-o-macrozoneamento-territorial-do-municipio-de-palmas-e-da-outras-providencias-2002-09-16.html>. Disponível em: 25 out. 2013.

PALMAS (Prefeitura municipal). Projeto de Lei complementar n. 14, de 7 de novembro de 2006. Dispõe sobre a política urbana do município de Palmas, formulada para atender ao pleno desenvolvimento das funções sociais da cidade e a garantia do bem-estar de seus habitantes, conforme estabelece a Constituição Federal de 1988, em seus artigos 182 e 183, e o Estatuto da Cidade, Lei Federal n. 10.257, de 10 de julho de 2001. Palmas, TO, 7 nov. 2006. Disponível em: <http://portal.palmas.to.gov.br/media/ doc/132.pdf>. Acesso em: 25 out. 2013.

PALMAS (Prefeitura municipal). Lei complementar n. 155, de 28 de dezembro de 2007. Dispõe sobre a política urbana no município de Palmas. Palmas, T0, 28 dez. 2007. Disponível em: <https://www.leismunicipais.com. br/cgi-local/topsearch.pl>. Acesso em: 25 out. 2013.

PALMAS (Prefeitura municipal). Lei complementar n. 185, de 10 de junho de 2009. Altera e acrescenta dispositivos na Lei n. 468, de 6 de janeiro de 1994. Palmas, T0, 10 jun. 2009. Disponível em: < http://portal.palmas. to.gov.br/media/doc/lei/13941_76_19_06_2009_16_37_ 45.pdf>. Acesso em: 25 out. 2013. 
PALMAS (Prefeitura municipal). Lei complementar n. 195, de 22 de dezembro de 2009. Dispõe sobre a regulamentação e aplicação do Parcelamento, Edificação e Utilização Compulsório - PEUC do solo urbano não edificado subutilizado ou não-utilizado, da forma que especifica. Palmas, TO, 22 dez. 2009. Disponível em: <http:// www.legisweb.com.br/legislacao/?id=176530>. Acesso em: 25 out. 2013.

PALMAS (Prefeitura municipal). Lei complementar n. 253, de 21 de junho de 2012. Autoriza a alienação das áreas que especifica; altera o $§ 3^{\circ}$ do art. 19 e $\S 1^{\circ}$ do art. 43 da Lei Complementar n. 155, de 28 de dezembro de 2007; revoga a Lei Complementar n. 245, de 17 de fevereiro de 2012, na forma que especifica. Palmas, T0, 21 jun. 2012. Disponível em: <https://www.leismunicipais. com.br/cgi-local/topsearch.pl>. Acesso em: 25 out. 2013.

RIBEIRO, L. C. Q. Segregação residencial: teorias, conceitos e técnicas. In: MOYSÉS, A. (Org.). Cidade, segregação urbana e planejamento. Goiânia: Editora da UCG, 2005.

ROLNIK, R. A Construção de uma política fundiária e de planejamento urbano para o país: avanços e desafios. In: BUENO, L. M. M.; CYMBALISTA, R. (Org.). Planos diretores municipais: novos conceitos de planejamento territorial. São Paulo: Annablume, 2007.
SANTOS, M. A urbanização brasileira. São Paulo: Edusp, 2009.

SANTOS Jr.., O. A; MONTANDON, D. T. (Org.). Os planos diretores municipais Pós-Estatuto da Cidade: balanço crítico e perspectivas. Rio de Janeiro: Letra Capital; Observatório das Metrópoles, 2011.

SOUZA, M. L. de. Mudar a cidade: uma introdução crítica ao planejamento e à gestão urbanos. Rio de Janeiro: Bertrand Brasil, 2010.

Recebido: 30/04/2012

Received: 04/30/2012

Aprovado: 13/05/2013

Approved: 05/13/2013 